\title{
USEFULNESS OF SERUM SCLEROSTIN AS A DIAGNOSTIC MARKER OF OSTEOPOROSIS IN A COHORT OF SPANISH POSTMENOPAUSAL WOMEN
}

I. Luque Fernández1,2, A. García Martín1,3, R. Reyes García1,4, S. Morales Santana1, B. García Fontana1, M. Muñoz Torres1 1 Bone metabolism Unit (RETICEF). Endocrinology Division. Hospital Universitario San Cecilio. Granada. Spain 2 Endocrinology Division, Hospital Virgen de la Salud. Toledo. Spain. 3 Endocrinology Division. Hospital Comarcal del Noroeste, Caravaca de la Cruz, Murcia.Spain Endocrinology Division. HGU Rafael Méndez, Lorca Murcia.Spain.

INTRODUCTION: Sclerostin, produced by osteocytes, is a potent inhibitor of Wht signaling and bone formation. The usefulness of its determination in clinical practice is not well established.

OBJECTIVES: The aims of this study were to evaluate serum sclerostin levels in a cohort of Spanish posmenopausal women, and to analyze its relationship with bone metabolism.

METHODS: We measured serum sclerostin in 97 posmenopausal women using enzyme-linked-immunosorbent assays (ELISA) .We also evaluated calciotropic hormones, bone turnover markers, bone mineral density (BMD), morphometric vertebral fractures, and prevalent fractures.

\section{RESULTS:}

\begin{tabular}{l|c|c|c|} 
& Mean & SD & Range \\
\hline Age (years) & 65,72 & 9,19 & $41-83$ \\
\hline Menopause (years) & 14,67 & 10,23 & $1-43$ \\
\hline Creatinine (mg/dl) & 0,80 & 0,18 & $0,5-1,5$ \\
\hline Calcium (mg/dl) & 9,48 & 0,42 & $8,7-10,6$ \\
\hline Phosphorus (mg/dl) & 3,66 & 0,46 & $2,7-5,05$ \\
\hline Sclerostin (pmol/l) & 36,70 & 14,40 & $14,9-104,9$ \\
\hline CTX (ng/ml) & 0,438 & 0,22 & $0,089-1,150$ \\
\hline Osteocalcin & 11,21 & 35,42 & $0,20-344$ \\
\hline BAP (ug/ml) & 17,92 & 13,40 & $6,4-113$ \\
\hline TRAP5 $\beta(\mathrm{U} / \mathrm{l})$ & 2,40 & 1,64 & $0,1-8,7$ \\
\hline $\begin{array}{l}\text { 25OH vitamin D } \\
\text { (mg/dl) }\end{array}$ & 19,15 & 12,92 & $1,6-72,2$ \\
\hline iPTH (pg/ml) & 52,15 & 20,94 & $19,9-117$ \\
\hline
\end{tabular}
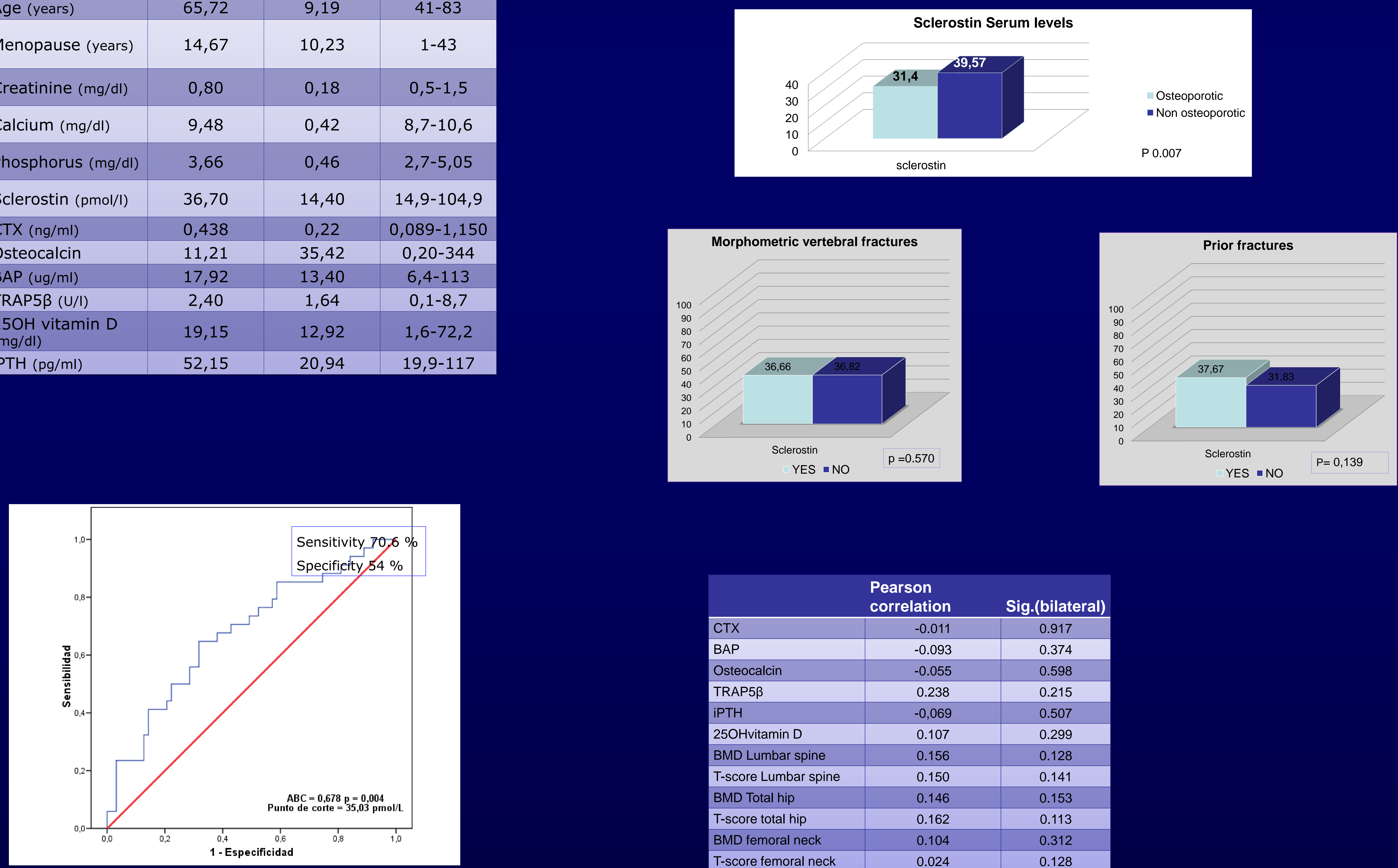

\begin{tabular}{l|c|c|} 
& $\begin{array}{l}\text { Pearson } \\
\text { correlation }\end{array}$ & Sig.(bilateral) \\
\hline CTX & -0.011 & 0.917 \\
\hline BAP & -0.093 & 0.374 \\
\hline Osteocalcin & -0.055 & 0.598 \\
\hline TRAP5 $\beta$ & 0.238 & 0.215 \\
\hline iPTH & $-0,069$ & 0.507 \\
\hline 25OHvitamin D & 0.107 & 0.299 \\
\hline BMD Lumbar spine & 0.156 & 0.128 \\
\hline T-score Lumbar spine & 0.150 & 0.141 \\
\hline BMD Total hip & 0.146 & 0.153 \\
\hline T-score total hip & 0.162 & 0.113 \\
\hline BMD femoral neck & 0.104 & 0.312 \\
\hline T-score femoral neck & 0.024 & 0.128 \\
\hline
\end{tabular}

\section{CONCLUSION:}

Circulating sclerostin levels were decreased in Spanish women with postmenopausal osteoporosis but serum sclerostin had limited usefulness as a diagnostic marker of osteoporosis. 